\title{
Atividade fitotóxica de um filtrado de cultura de Cercospora brachiata sobre sementes e parte aérea de Amaranthus viridis
}

\section{Phytotoxic activity of Cercospora brachiata culture filtrate on seeds and aerial part of Amaranthus viridis}

\author{
Neiliane Aparecida da Silva \\ Instituto Federal do Triângulo Mineiro Campus Uberaba \\ E-mail: nena.a@hotmail.com \\ OrcID: https://orcid.org/0000-0003-2945-3487
}

\author{
Bruno Sérgio Vieira \\ Universidade Federal de Uberlândia, Campus Monte Carmelo \\ E-mail: brunovieira@ufu.br \\ OrclD: https://orcid.org/0000-0001-8130-8100
}

Gustavo Moreira Ribeiro

Universidade Federal de Uberlândia, Campus Monte Carmelo

E-mail: gustavo.m.01@hotmail.com

OrcID: https://orcid.org/0000-0002-9495-3288

John Kenedy Rodrigues Pereira Felisbino

Instituto de Química, Universidade Federal de Uberlândia, Campus Santa Mônica

E-mail: johnkenedy7@hotmail.com

OrclD: https://orcid.org/0000-0002-8049-5052

Raquel Maria Ferreira de Sousa

Instituto de Química, Universidade Federal de Uberlândia, Campus Santa Mônica

E-mail: rsousa@ufu.br

OrclD: https://orcid.org/0000-0003-1509-2721

Resumo: O caruru (Amaranthus spp.) é considerado uma espécie daninha de difícil manejo e de grande importância para agricultura. O objetivo do trabalho foi avaliar a atividade fitotóxica de um filtrado de cultura produzido por Cercospora brachiata, patógeno foliar de $A$. viridis, sobre a germinação de sementes e desenvolvimento de plantas de caruru, sorgo e pepino. O fungo foi cultivado em meio de cultura líquido e o extrato fúngico bruto, obtido a partir da extração em acetato de etila, foi concentrado e submetido a teste para avaliação da atividade fitotóxica sobre sementes e plantas de caruru, sorgo e pepino. Para o teste com sementes, 20 sementes de cada espécie foram transferidas para placas de Petri contendo papel de germinação embebido com $3 \mathrm{~mL}$ de cada tratamento: T1 (extrato fúngico bruto + dimetilsulfóxido $\left(\mathrm{CH}_{3}\right)_{2} \mathrm{SO}$ ), T2 (dimetilsulfóxido $\left(\mathrm{CH}_{3}\right)_{2} \mathrm{SO}$ ) (branco) e T3 (água estéril). Para o experimento com plantas, foram utilizados os mesmos tratamentos descritos anteriormente, acrescidos de Tween 80 a 0,05\% $\left(\mathrm{m} \mathrm{v}^{-1}\right)$. Cada parcela continha uma planta de cada espécie por vaso, cinco repetições e diferentes estádios fenológicos (2, 4 e 6 folhas). Em cada estádio foram feitas 3 aplicações de $3 \mathrm{~mL}_{\text {planta }}{ }^{-1} \mathrm{em}$ intervalos de 3 dias. $O$ extrato fúngico de $C$. brachiata inibiu totalmente a germinação de sementes de $A$. viridis. Metabólitos de $C$. brachiata apresentam atividade inibitória pronunciada sobre o crescimento de plantas de $A$. viridis e não afetaram nenhum parâmetro fisiológico tanto para pepino quanto para sorgo. Foram identificados ácidos de cadeia longa e ésteres de ácidos graxos a partir do filtrado de cultura de C. brachiata. 
Palavras-chave: bioherbicida, metabólitos, isolamento guiado por bioensaio, caruru, fitotoxinas

\begin{abstract}
Slender amaranth (Amaranthus spp.) is considered a weedy species of difficult management and of great importance for agriculture. The objective of this work was to evaluate the phytotoxic activity of a extract filtrate produced by Cercospora brachiata, a foliar pathogen of $A$. viridis, on seed germination and development of slender amaranth, sorghum and cucumber plants. The fungus was cultivated in liquid culture media and the fungus extract obtained from the ethyl acetate extraction was concentrated and tested for phytotoxic activity on slender amaranth, sorghum and cucumber seeds and plants. For the seed test, 20 seeds of each species were transferred to Petri dishes containing germination paper soaked with $3 \mathrm{~mL}$ of each treatment: T1 (extract fungus + dimethylsulfoxide $\left(\mathrm{CH}_{3}\right)_{2} \mathrm{SO}$ ), T2 (dimethylsulfoxide $\left(\mathrm{CH}_{3}\right)_{2} \mathrm{SO}$ ) (white) and T3 (sterile water). For the plant experiment the same treatments described above were used, plus $0.05 \%$ Tween $80\left(\mathrm{~m} \mathrm{v}^{-1}\right)$. Each plot contained one plant of each species per pot, five replicates and different phenological stages (2, 4 and 6 leaves). At each stage 3 applications of $3 \mathrm{~mL}$ planta ${ }^{-1}$ were made at 3 days intervals. The fungal extract of $C$. brachiata totally inhibited the germination of $A$. viridis seeds. Metabolites of $C$. brachiata show pronounced inhibitory activity on the growth of $A$. viridis plants and did not affect any physiological parameters for both cucumber and sorghum. Long chain acids and fatty acid esters were identified from the culture filtrate of $C$. brachiata.
\end{abstract}

Keywords: bioherbicide, metabolites, bioassay-guided fractionation, slender amaranth, phytotoxins

Data de recebimento: 04/04/2019

Data de aprovação: 30/01/2020

DOI: https://doi.org/10.30612/agrarian.v13i49.9660

\title{
Introdução
}

As plantas daninhas são um dos fatores mais limitantes para a produção agrícola, podendo limitar o desenvolvimento das culturas em vários aspectos (Oliveira \& Brighenti, 2018). Espécies do gênero Amaranthus, conhecidas popularmente como "caruru", estão presentes em todas as áreas agrícolas do Brasil. São plantas anuais, que podem-se multiplicar por sementes, possuindo alto potencial de interferência nas culturas agrícolas, proporcionado pela rápida captura de recursos naturais do ambiente, tais como água e nutrientes durante os estádios iniciais das culturas (Carvalho et al., 2008). Um problema adicional se refere à resistência a herbicidas químicos de alguns biótipos de Amaranthus (Francischini et al., 2014).

Os métodos utilizados para o manejo de plantas daninhas são: mecânico, químico, cultural, além de pesquisas relacionadas ao controle biológico, alelopatia e físicos (Oliveira \& Brighenti, 2018). Os sistemas agrícolas produtivos estão ficando a cada ano mais complexos e para o sucesso no manejo das plantas daninhas necessita-se cada vez mais de integração de diferentes métodos de controle (Oliveira \& Brighenti, 2018). Esse avanço na integração de diferentes métodos de controle se deve principalmente pelo elevado custo no controle químico das plantas daninhas, surgimento de biótipos com resistência a herbicidas químicos e ao aumento da demanda por produtos orgânicos.

Vários relatos de manejo biológico de plantas daninhas têm sido estudados, bem como o uso de bioherbicidas a base de plantas e fungos fitopatogênicos (Javaid et al., 2017). Dentre as possibilidades mais promissoras por tecnologias inovadoras para o manejo de plantas daninhas, destaca-se a busca de novas moléculas produzidas por microrganismos com ação bioherbicida. Toxinas com potencial ação herbicida produzidas por fungos fitopatogênicos são capazes de penetrar na planta hospedeira, desintegrar sua estrutura celular e induzir a produção de lesões necróticas ou halo clorótico, com a vantagem de não serem tóxicas aos mamíferos e serem facilmente degradadas no ambiente (Charudattan, 1991; Varejão et al., 2013).

Durante um levantamento de fungos fitopatogênicos associados a Amaranthus spp. na região do Alto Paranaíba (Minas Gerais), foram observadas plantas doentes de caruru (Amaranthus viridis L.) apresentando lesões foliares no município de Monte Carmelo (Minas Gerais). Procedeu-se então, com a coleta destas plantas que foram encaminhadas para o Laboratório de Microbiologia e Fitopatologia (LAMIF) da Universidade Federal de Uberlândia - Campus de Monte Carmelo) para preparo de lâminas e isolamento do fungo em cultura pura.

Agrarian, Dourados, v. 13, n. 49, p. 339-351, 2020. 
O fungo foi identificado morfologicamente como Cercospora brachiata e trata-se do primeiro relato desse fungo no Brasil associado à Amaranthus viridis L. (Vieira et. al., 2019).

Vários compostos isolados do gênero Cercospora têm sido relatados na literatura como produtores de fitotoxinas, como a cercosporina (Lynch \& Geoghegan, 1977). A aplicação de suspensões de conídios de C. brachiata sobre $A$. viridis resulta em lesões foliares que levam a uma intensa desfolha nas plantas inoculadas. Essas observações levaram à hipótese de que o fungo possa produzir fitotoxinas in vitro capazes de causar danos às sementes e parte aérea de plantas de caruru.

Diante disso, o objetivo desse trabalho foi avaliar a atividade fitotóxica de um filtrado de cultura do fungo Cercospora brachiata sobre a germinação de sementes e desenvolvimento da parte aérea de Amaranthus viridis $\mathrm{L}$. (planta alvo). Além de $A$. viridis foram incluídas no trabalho mais duas espécies: pepino (Cucumis sativus L.) e sorgo (Sorghum bicolor L), como representante de uma eudicotiledônea e uma monocotiledônea, respectivamente.

\section{Material e Métodos}

O isolado do fungo Cercospora brachiata utilizado no trabalho faz parte da Coleção do LAMIF da Universidade Federal de Uberlândia - Campus Monte Carmelo.

Cercospora brachiata foi isolado a partir de tecidos infectados de $A$. viridis, no qual foi cultivado em placas de Petri contendo o meio de cultura batata-dextrose-ágar (BDA), a $25^{\circ} \mathrm{C}$ por sete dias. Discos de micélio de 10 $\mathrm{mm}$ de diâmetro, provenientes da periferia de culturas em crescimento ativo foram assepticamente transferidos para frascos erlenmeyers de $500 \mathrm{~mL}$ contendo $250 \mathrm{~mL}$ do meio de cultura líquido Jenkins-Prior modificado (Fargues et al., 2001). Os frascos foram, em seguida, acondicionados em agitador orbitar tipo shaker a 150 rpm, no escuro, a $25^{\circ} \mathrm{C}$ durante 21 dias a fim de permitir o crescimento micelial do fungo e a produção de possíveis toxinas (metabólitos) secretadas no meio de cultura.

As culturas foram filtradas em dupla gaze e por um disco de papel de filtro qualitativo, usando-se funil de Buchner, sob vácuo, para eliminação do micélio. Posteriormente, o filtrado da cultura foi submetido ao processo de cromatografia.

Para tal, o filtrado da cultura foi extraído com acetato de etila $(3 \times 1 \mathrm{~L})$. Sendo aferido o $\mathrm{pH}$ do caldo por meio de papel indicador, apresentando $\mathrm{pH} 5,2$. O extrato em acetato de etila foi submetido à secagem utilizando $\mathrm{MgSO}_{4}$ anidro, filtrado e concentrado em evaporador rotativo a $40{ }^{\circ} \mathrm{C}$. O extrato obtido foi analisado por espectrometria de massas de alta resolução por ionização por electrospray. $\mathrm{Na}$ sequência, realizou-se o fracionamento através de cromatografia em coluna, utilizando sílica-gel 60 (70-230 mesh) ou sephadex- $\mathrm{LH}_{2} 0$ como fase estacionária. A escolha da fase estacionária se deu por meio do perfil da separação observada por cromatografia em camada delgada (CCD). O tipo de eluente também foi escolhido com base no perfil de separação na CCD. Os compostos isolados foram analisados por infravermelho, espectrometria de massas e ressonância magnética nuclear, a fim de identificar a estrutura química desses compostos. Os solventes utilizados na extração e nas separações cromatográficas foram de grau analítico ou grau HPLC; e o grau de pureza do solvente foi escolhido com base no tipo de análise. A cromatografia em camada delgada foi realizada utilizando cromatoplacas de alumina, impregnada com sílica-gel $60 \mathrm{~F}_{254}$, com 0,25 mm de espessura e revelação com luz ultravioleta $(254$ e 366 nm). Como revelador de compostos orgânicos utilizou-se solução de vanilina sulfúrica.

Experimento biológico 1: A fitotoxicidade do filtrado de cultura de C. brachiata sobre sementes sadias de caruru, pepino e sorgo foi avaliada segundo metodologia proposta por Macias et al. (2000). Para isso, 20 sementes de cada espécie foram transferidas para placas de Petri de $90 \mathrm{~mm}$ de diâmetro, contendo papel de germinação (Germitest ${ }^{\circledR}$ ) embebido em $3 \mathrm{~mL}$ dos seguintes tratamentos T1: extrato bruto extraído com acetato de etila diluído em dimetilsulfóxido $\left(\mathrm{CH}_{3}\right)_{2} \mathrm{SO}-0,1 \mathrm{~g} \mathrm{~L}^{-1} ; \mathrm{T} 2$ : água destilada com dimetilsulfóxido $\left(\mathrm{CH}_{3}\right)_{2} \mathrm{SO}-0,1$ $\mathrm{g} \mathrm{L}^{-1}$ (Branco) e T3: água destilada estéril. As placas foram mantidas em incubadoras tipo BOD a $25{ }^{\circ} \mathrm{C}$ e fotoperíodo de $12 \mathrm{~h}$. Com isso, após o período proposto para cada espécie, prosseguiram-se com as avaliações de germinação conforme prescrito nas Regras para Análise de Sementes - RAS (Brasil, 2009). Avaliou-se a

Agrarian, Dourados, v. 13, n. 49, p. 339-351, 2020. 
porcentagem de sementes germinadas, o comprimento da protusão radicular $(\mathrm{cm})$ e as porcentagens de inibição da germinação das sementes e da protusão radicular, calculadas em relação ao T2 (Branco). O delineamento experimental utilizado foi inteiramente casualizado, com sete repetições. Os dados foram submetidos à análise de variância (ANAVA, $p<0,05$ ), e as médias, comparadas pelo teste de Tukey.

Experimento biológico 2: O experimento com plantas de caruru, sorgo e pepino foi conduzido em casa de vegetação da UFU/Campus Monte Carmelo -MG, em delineamento de blocos casualizados (DBC), com três tratamentos (T1: extrato bruto extraído com acetato de etila diluído em dimetilsulfóxido $\left(\mathrm{CH}_{3}\right)_{2} \mathrm{SO}-0,1 \mathrm{~g} \mathrm{~L}^{-1}+$ Tween 80 a 0,05\% (m/v); T2: água destilada com dimetilsulfóxido $\left(\mathrm{CH}_{3}\right)_{2} \mathrm{SO}-0,1 \mathrm{~g} \mathrm{~L}^{-1}+$ Tween 80 a $0,05 \%(\mathrm{~m}$ $\left.\mathrm{v}^{-1}\right)$ (Branco) e T3: água destilada com Tween 80 a 0,05\% ( $\left.\mathrm{m} \mathrm{v}^{-1}\right)$, utilizado como testemunha. Foram utilizadas cinco repetições, sendo cada repetição representada por um vaso de 14 litros contendo substrato 2:1:0,5 (solo/areia/esterco curtido), com uma planta por vaso. Foram avaliados três estádios fenológicos diferentes: 2 , 4 e 6 folhas totalmente desenvolvidas, e as pulverizações foram iniciadas quando cada espécie atingiu os estádios em questão. Foram feitas em cada estádio 3 pulverizações de cada tratamento com auxílio de borrifador manual, com intervalo de 3 dias entre as aplicações; sendo $3 \mathrm{~mL}$ do respectivo tratamento por planta. Foi realizado um experimento para cada espécie e para cada estádio fenológico. Os vasos permaneceram em casa de vegetação durante todo o experimento, sendo irrigados diariamente.

Após a terceira aplicação, em cada estádio fenológico, as plantas foram mantidas em casa de vegetação por mais 20 dias. Ao final do experimento foi determinado o índice de clorofila com o auxílio de um clorofilômetro da marca comercial ClorofiLOG $₫$ modelo CFL 1030. Em seguida, as plantas foram cuidadosamente lavadas sob água corrente, separando as raízes e a parte aérea. Os parâmetros avaliados foram: comprimento do sistema radicular $(\mathrm{cm})$ e parte aérea $(\mathrm{cm})$, peso fresco $(\mathrm{g})$ e seco $(\mathrm{g})$ do sistema radicular e da parte aérea. Os dados obtidos foram submetidos a análise de variância $p<0,05$ ), e as médias, comparadas pelo teste de Tukey a $5 \%$ do nível de significância.

\section{Resultados e Discussão}

O extrato fúngico de $C$. brachiata inibiu totalmente a germinação de sementes de $A$. viridis, aos 14 dias de avaliação. Não foram observadas diferenças entre os tratatmentos para o número de sementes germinadas tanto para C. sativus quanto para S. bicolor (Tabela 1). O efeito inibitório do extrato fúngico sobre a germinação das sementes foi de: $100 \%$ de inibição para $A$ viridis, $6,43 \%$ para S. bicolor e $4,5 \%$ para C. sativus (Tabela 1 ).

Constatou-se inibição do crescimento da protrusão radicular de caruru, sorgo e pepino após o contato com o papel-filtro embebido com a solução contendo o extrato fúngico bruto (Tabela 1).

A inibição do crescimento da protrusão radicular observada para a espécie daninha $A$. viridis foi de $100 \%$ e para o sorgo de $33,17 \%$. A menor porcentagem de inibição observada foi de 20,49 \% para o pepino. Em relação ao comprimento da protrusão radicular houve diferença entre o extrato fúngico e o T2 (Branco) em $A$. viridis e S. bicolor (Tabela 1). 
Tabela 1. Efeito do extrato fúngico bruto produzido por Cercospora brachiata sobre a germinação e o desenvolvimento da protusão radicular de C. sativus, S. bicolor e Amaranthus viridis

\begin{tabular}{|c|c|c|c|c|}
\hline Tratamento & $\begin{array}{l}\text { Porcentagem de } \\
\text { sementes } \\
\text { germinadas* }\end{array}$ & $\begin{array}{l}\text { Comprimento da } \\
\text { protrusão radicular } \\
(\mathrm{cm})^{*}\end{array}$ & $\begin{array}{c}\text { Porcentagem de } \\
\text { inibição da } \\
\text { germinação } \\
(\%)\end{array}$ & $\begin{array}{l}\text { Porcentagem de } \\
\text { inibição da } \\
\text { protrusão radicular } \\
(\%)\end{array}$ \\
\hline \multicolumn{5}{|c|}{ A. viridis } \\
\hline T1 & $0.00 \mathrm{~B}$ & $0.00 \mathrm{~B}$ & 100 & 100 \\
\hline T2 & $6.71 \mathrm{~A}$ & $1.15 \mathrm{~A}$ & & \\
\hline T3 & $8.28 \mathrm{~A}$ & $1.64 \mathrm{~A}$ & & \\
\hline \multicolumn{5}{|c|}{ C. sativus } \\
\hline T1 & $18.00 \mathrm{~A}$ & $3.22 \mathrm{~B}$ & 4.5 & 20.49 \\
\hline T2 & $18.85 \mathrm{~A}$ & $4.05 \mathrm{AB}$ & & \\
\hline T3 & $18.42 \mathrm{~A}$ & $4.91 \mathrm{~A}$ & & \\
\hline \multicolumn{5}{|c|}{ S. bicolor } \\
\hline T1 & $16.57 \mathrm{~A}$ & $4.23 \mathrm{~B}$ & 6.43 & 33.17 \\
\hline T2 & $17.71 \mathrm{~A}$ & $6.33 \mathrm{~A}$ & & \\
\hline T3 & $18.00 \mathrm{~A}$ & $5.51 \mathrm{~A}$ & & \\
\hline
\end{tabular}

*Médias seguidas pelas mesmas letras, na coluna, não diferem estatisticamente entre si, pelo teste de Tukey a 0,05\% de significância. T1: extrato bruto extraído com acetato de etila diluído em dimetilsulfóxido $\left(\mathrm{CH}_{3}\right)_{2} \mathrm{SO}-0,1 \mathrm{~g} / \mathrm{L}$; T2: água destilada com dimetilsulfóxido $\left(\mathrm{CH}_{3}\right)_{2} \mathrm{SO}-0,1 \mathrm{~g} / \mathrm{L}$ (Branco) e T3: água destilada estéril

Javaid et al. (2011) avaliaram quatro espécies do fungo pertencente ao gênero Drechslera sobre Parthenium hysterophorus L., reduzindo, dependendo da espécie, a germinação, o comprimento da parte aérea, a biomassa, o comprimento de raiz e a biomassa fresca das raízes de $P$. hysterophorus em 43 a $77 \%, 77$ a $82 \%, 69$ a $82 \%, 90$ a $92 \%$ e 67 a $83 \%$, respectivamente.

Segundo Macias et al. (2000), uma taxa de inibição de $40 \%$ no crescimento da protrusão radicular poderia ser considerada de grande importância sobre o ponto de vista fitotóxico.

Santos et al. (2008) avaliaram substâncias químicas do fungo Pestalotiopsis guepinii isolado a partir da espécie Virola michelii, quanto ao desenvolvimento radicular e do hipocótilo das plantas daninhas, malícia (Mimosa pudica) e mata-pasto (Senna obtusifolia), em relação ao desenvolvimento da radícula. Os extratos metanólicos $\mathrm{MeOH}^{-1} \mathrm{e} \mathrm{MeOH}^{-2}$ apresentaram, respectivamente, 49 e $48 \%$ de inibição para a espécie malícia e 51 e $58 \%$, respectivamente, para a espécie mata-pasto. Para o desenvolvimento do hipocótilo, frente à espécie malícia, os extratos $\mathrm{MeOH}^{-1}$ e $\mathrm{MeOH}^{-2}$ apresentaram, respectivamente, 55 e $51 \%$ de inibição e, para a espécie mata-pasto, 48 e $43 \%$, respectivamente.

Para a identificação dos compostos no presente trabalho foi realizada uma análise em CG-EM (Cromatografia gasosa acoplada a espectrômetro de massas) do extrato fúngico de C. brachiata extraído com acetato de etila, os quais seguem abaixo (Figura 1 e Tabela 2). Os compostos isolados, que foram identificados pelo software do equipamento, estão discriminados entre si por asteriscos $\left(^{*}\right)$.

A análise em CG-EM do extrato do fúngico de $C$. brachiata extraído com acetato de etila mostrou um espectro de absorção (Figura 1) característico de ácidos graxos de cadeia longa e ésteres de ácidos graxos, com bandas de absorção em: 39,1 (NI); 42,4/ 43,0 (1,4-diaza-2,5-dioxo-3-isobutilbiciclo [4.3.0] nonano); 43,2 (Hexadecanoato de metila), 48,4 (Linoleato de metila), 48,6 (10-Octadecenoato de metila), 49,5 (Octadecanoato de metila), 56,1 (Ergotaman-3 ', 6', 18-triona, 9,10-di-hidro-12'-hidroxi-2'-metil-5 '- (fenilmetil) -, (5' $\alpha, 10 \alpha)$ ). Esses ácidos graxos e ésteres de ácidos graxos identificados são provavelmente as substâncias responsáveis pelas inibições do crescimento da protrusão radicular de caruru, sorgo e pepino; e pela inibição total da germinação de sementes de $A$. viridis. 


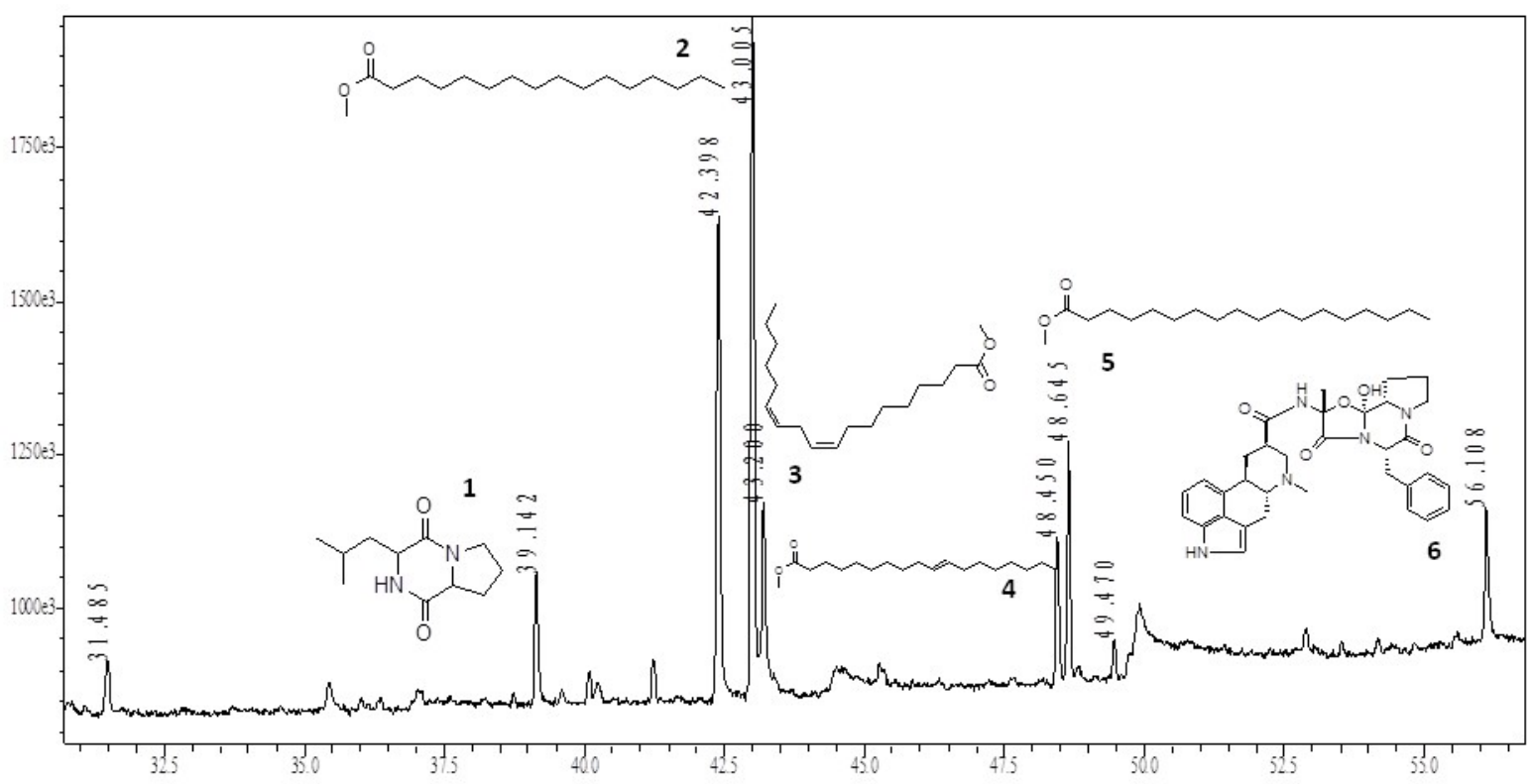

Figura 1. CG-EM - Cromatograma do extrato acetato de etila da cultura fúngica de Cercospora brachiata. Fonte: Felisbino J. K. R.P (2019)

Tabela 2. Compostos identificados por CG-EM do extrato acetato de etila da cultura fúngica de Cercospora brachiata

\begin{tabular}{lccccc}
\hline \multicolumn{1}{c}{ COMPOSTO } & TR & Al analisado & Al literatura* & Biblioteca & IS \\
\hline $\mathrm{NI}$ & 39,1 & - & - & - & - \\
1,4-diaza-2,5-dioxo-3-isobutilbiciclo & $42,4 /$ & - & - & WILEY7 & 92 \\
[4.3.0] nonano & 43,0 & & & WILEY229 & 94 \\
Hexadecanoato de metila & 43,2 & 1935 & 1933 & NIST27 & 93 \\
Linoleato de metila & 48,4 & 2101 & 2092 & WILEY7 & 96 \\
10-Octadecenoato de metila & 48,6 & 2108 & 2110 & WILEY229 & 95 \\
Octadecanoato de metila & 49,5 & 2138 & 2135 & WILEY7 & 90 \\
Ergotaman-3 ', 6', 18-triona, 9,10-di- & 56,1 & - & - & NIST27 & 86
\end{tabular}

hidro-12'-hidroxi-2'-metil-5 '-

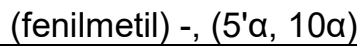

Nota: TR: tempo de retenção, Al: índice aritmético; IS: índice de similaridade; *Adams (2007) ou NIST (2018). Fonte: Felisbino J. K. R.P (2019)

A atividade fitotóxica de ácidos graxos de cadeias longas produzidas por fungos fitopatogênicos sobre plantas daninhas tem sido demonstrada em diferentes estudos. Varejão et al. (2013) avaliaram a produção in vitro de fitotoxinas sob diferentes condições de cultivo do fungo Alternaria euphorbiicola. Os filtrados das culturas em meio Jenkins Prior modificado e Caldo de Vegetais inibiram em 100 e $50 \%$ a germinação de sementes de Euphorbia heterophylla e o crescimento radicular das sementes entre 100 e 82,7 \%, respectivamente. O meio de Jenkins-Prior foi submetido a extração com acetato de etila $(3 \times 1 \mathrm{~L})$, seguida por fracionamento e bioensaios. Uma fração cromatográfica constituída majoritariamente por ácidos graxos de cadeia longa ocasionou halos cloróticos e necrose nas folhas, tal qual como observado por meio da inoculação de $E$. heterophylla com conídios de $A$. euphorbiicola.

O fracionamento de um extrato em acetato de etila de uma cultura do fungo Corynespora cassiicola em meio sólido forneceu frações cromatográficas capazes de inibir o desenvolvimento de Physalis ixocarpa, permitindo a identificação do extrato mais ativo (CAE), de onde se isolou o composto ergosta-4,6,8(14),22tetraen-3-ona (C1) e ácidos graxos. O extrato de CAE causou 37, 42 e 13\% de inibição na germinação de sementes, na radícula e no crescimento de P. ixocarpa, respectivamente (Passos et al., 2010). Souza Filho e 
Duarte (2007) avaliaram a atividade fitotóxica do filtrado produzido por Fusarium solani f.sp. pipers em concentrações de 1 a $4 \%$ do extrato fúngico sobre a germinação de sementes e desenvolvimento do hipocótilo e radícula de malícia (Mimosa pudica) e mata-pasto (Senna obtusifolia). A inibição máxima observada foi na concentração de $4 \%$, sendo maiores os efeitos inibitórios sobre $M$. pudica em relação a $S$. obtusifolia. As inibições sobre o desenvolvimento da radícula foram superiores a $50 \%$ para $M$. pudica e de $30 \%$ para $S$. obtusifolia.

Os metabólitos de Aspergillus niger preparados em caldo de extrato de malte e caldo de batata e dextrose foram avaliados quanto à sua atividade herbicida contra Parthenium hysterophorus, em duas concentrações, original $(X)$ e diluída $(1 / 2 X)$. Os metabólitos originais preparados em caldo extrato de malte inibiram completamente a germinação de sementes da planta daninha, ao passo que os preparados em caldo de batata e dextrose reduziram a germinação em $89 \%$ em relação ao controle (Bashir et al., 2018).

No experimento biológico 2, delineado em casa de vegetação, constatou-se que a pulverização de metabólitos fúngicos de $C$. brachiata (T1) reduziu a altura das plantas de caruru em relação aos tratamentos T2 e T3 em plantas com 2, 4 e 6 pares de folhas (Tabela 3, Figura 2). A pulverização do extrato fúngico de $C$. brachiata reduziu em 53,63 \%, 36,64 \% e 16,64\% a altura das plantas de caruru nos estádios de 2 , 4 e 6 folhas desenvolvidas, respectivamente. Podemos inferir que os ácidos graxos e ésteres de ácidos graxos identificados no extrato fúngico inibem o crescimento das plantas de caruru nos três estádios fenológicos testados, com inibição maior em estádios iniciais de desenvolvimento das plantas. De forma similar o extrato fúngico de $C$. brachiata reduziu o comprimento das raízes de caruru nos três estádios fenológicos testados, com inibições de $50,31 \%, 39,95 \%$ e 15,58 \% no sistema radicular de plantas de caruru nos estádios de 2, 4 e 6 folhas desenvolvidas, respectivamente (Figura 2 e Tabela 3).

$O$ extrato fúngico de $C$. brachiata reduziu o peso fresco e seco da parte aérea das plantas de caruru nos estádios de 2 e 4 folhas desenvolvidas, com inibições de $86,12 \%$ e 41,76\% para peso fresco da parte aérea, e 82,7 e 43,19\% para peso seco da parte aérea nos estádios de 2 e 4 folhas, respectivamente. Para biomassa de raiz foi observado uma diminuição apenas para peso fresco do sistema radicular nos estádios de 2 e 4 folhas desenvolvidas, com inibições de $87,7 \%$ e $50 \%$ para os estádios de 2 e 4 folhas, respectivamente (Tabela 3, Figura 2). Podemos constatar que as maiores inibições na biomassa das plantas de caruru foram observadas nos estágios iniciais de desenvolvimento das plantas. Não foram observadas alterações nos índices de clorofila A e B em plantas da caruru tratados com o extrato fúngico nos três estádios fenológicos testados.

O estádio vegetativo da planta daninha interfere no seu controle, sendo fundamental definir o estádio ideal para se atingir a eficiência esperada com o tratamento, podendo ter uma redução de doses e custo (Conte, 2017). O uso de controle químico em algumas espécies de plantas daninhas também apresenta maior eficiência nos estádios iniciais (Oliveira \& Brighenti, 2018). Gossler et al. (2015) constataram que houve maior controle de buva aos 21 dias após a aplicação com saflufenacil isolado e em combinação com o glyphosate, com controle superior a $94 \%$. 


\section{(2) Acrarian}

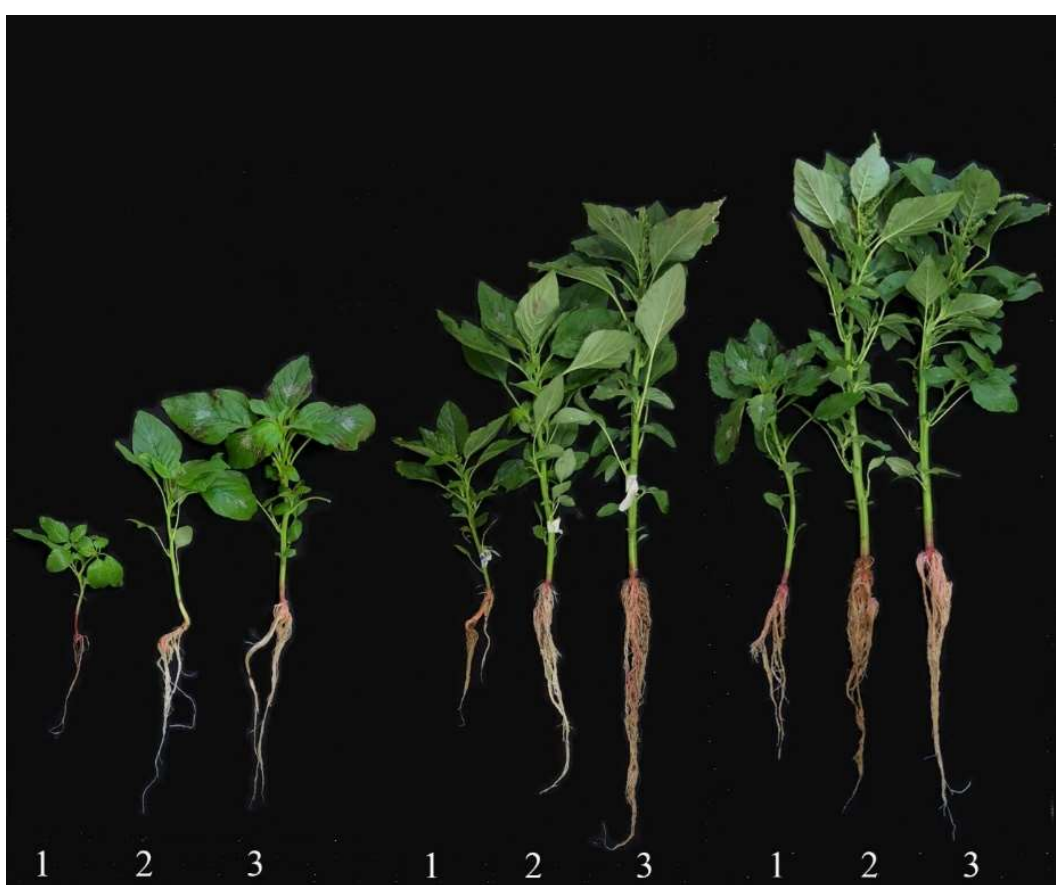

Figura 2. Plantas de Amaranthus viridis em diferentes estádios fenológicos, 20 dias após a terceira aplicação dos tratamentos T1 (Extrato fúngico bruto), T2 (Branco) e T3 (Água)

Tabela 3. Efeito do extrato fúngico bruto produzido por Cercospora brachiata sobre o desenvolvimento de parte aérea e sistema radicular de Amaranthus viridis em diferentes estádios fenológicos

Caruru (Amaranthus viridis)

\begin{tabular}{|c|c|c|c|}
\hline Estádio Fenológico & 2 folhas & 4 folhas & 6 folhas \\
\hline Tratamentos & \multicolumn{3}{|c|}{ Altura de parte aérea $(\mathrm{cm})$} \\
\hline $\mathrm{T} 1$ & $9.02 \mathrm{~B}$ & $25.12 \mathrm{~B}$ & $35.01 \mathrm{C}$ \\
\hline T2 & $20.86 \mathrm{~A}$ & $41.85 \mathrm{~A}$ & $42.00 \mathrm{~B}$ \\
\hline \multirow[t]{2}{*}{ T3 } & $23.11 \mathrm{~A}$ & $46.30 \mathrm{~A}$ & $52.77 \mathrm{~A}$ \\
\hline & \multicolumn{3}{|c|}{ Comprimento da Raiz (cm) } \\
\hline T1 & $9.02 \mathrm{~B}$ & $22.47 \mathrm{~B}$ & $34.73 \mathrm{~B}$ \\
\hline T2 & $19.64 \mathrm{~A}$ & $38.67 \mathrm{~A}$ & $42.49 \mathrm{~A}$ \\
\hline \multirow[t]{2}{*}{ T3 } & $23.03 \mathrm{~A}$ & $39.90 \mathrm{~A}$ & $42.28 \mathrm{~A}$ \\
\hline & \multicolumn{3}{|c|}{ Peso fresco da parte aérea (g) } \\
\hline T1 & $1.79 \mathrm{~B}$ & $26.85 \mathrm{~B}$ & $33.39 \mathrm{~B}$ \\
\hline T2 & $12.96 \mathrm{~A}$ & $46.11 \mathrm{~A}$ & $41.41 \mathrm{AB}$ \\
\hline \multirow[t]{2}{*}{ T3 } & $13.72 \mathrm{~A}$ & $49.51 \mathrm{~A}$ & $51.65 \mathrm{~A}$ \\
\hline & \multicolumn{3}{|c|}{ Peso fresco de raiz $(\mathrm{g})$} \\
\hline T1 & $0.41 \mathrm{~B}$ & $6.40 \mathrm{~B}$ & $10.88 \mathrm{~B}$ \\
\hline $\mathrm{T} 2$ & $3.39 \mathrm{~A}$ & $12.80 \mathrm{~A}$ & $13.27 \mathrm{~B}$ \\
\hline \multirow[t]{2}{*}{ T3 } & $3.63^{\mathrm{a}}$ & $14.66 \mathrm{~A}$ & $18.47 \mathrm{~A}$ \\
\hline & \multicolumn{3}{|c|}{ Peso seco da parte aérea $(\mathrm{g})$} \\
\hline T1 & $0.31 \mathrm{~B}$ & $2.67 \mathrm{~B}$ & $3.94 \mathrm{~B}$ \\
\hline T2 & $1.80 \mathrm{~A}$ & $4.70 \mathrm{~A}$ & $4.50 \mathrm{~B}$ \\
\hline \multirow{2}{*}{ T3 } & $1.87 \mathrm{~A}$ & $5.12 \mathrm{~A}$ & $5.63 \mathrm{~A}$ \\
\hline & \multicolumn{3}{|c|}{ Peso seco da raiz (g) } \\
\hline T1 & $0.77 \mathrm{~A}$ & $0.66 \mathrm{~B}$ & $1.46 \mathrm{~B}$ \\
\hline T2 & $0.76 \mathrm{~A}$ & $1.25 \mathrm{AB}$ & $1.67 \mathrm{AB}$ \\
\hline
\end{tabular}

Agrarian, Dourados, v. 13, n. 49, p. 339-351, 2020.

Este obra está licenciada com uma Licença Creative Commons Atribuição-NãoComercial-CompartilhaIqual 3.0 Brasil. 
T3

\begin{tabular}{cccc} 
T3 & $0.44 \mathrm{~A}$ & $1.86 \mathrm{~A}$ & $2.38 \mathrm{~A}$ \\
\hline & & Clorofila $\mathbf{A}\left(\boldsymbol{\mu g} \cdot \mathbf{c m}^{-2}\right)$ & $32,66 \mathrm{~A}$ \\
T1 & $29,12 \mathrm{~A}$ & $28,14 \mathrm{~B}$ & $32,86 \mathrm{~A}$ \\
T2 & $27,60 \mathrm{~A}$ & $31,00 \mathrm{AB}$ & $33,36 \mathrm{~A}$ \\
T3 & $29,66 \mathrm{~A}$ & $32,9 \mathrm{~A}$ & $11,86 \mathrm{~A}$ \\
& & Clorofila B $\left(\boldsymbol{\mu g} . \mathbf{c m}^{-2}\right)$ & $11,92 \mathrm{~A}$ \\
T1 & $9,30 \mathrm{~A}$ & $8,78 \mathrm{~B}$ & $13,80 \mathrm{~A}$ \\
\hline T2 & $8,92 \mathrm{~A}$ & $11,32 \mathrm{AB}$ & $12,24 \mathrm{~A}$ \\
T3 & $9,32 \mathrm{~A}$ &
\end{tabular}

* Médias seguidas pela mesma letra maiúscula na coluna não diferem entre si pelo teste de Tukey a $5 \%$ de probabilidade. T1: extrato bruto extraído com acetato de etila diluído em dimetilsulfóxido $\left(\mathrm{CH}_{3}\right)_{2} \mathrm{SO}-0,1 \mathrm{~g} / \mathrm{L} ; \mathrm{T} 2$ : água destilada com dimetilsulfóxido $\left(\mathrm{CH}_{3}\right)_{2} \mathrm{SO}-0,1 \mathrm{~g} / \mathrm{L}$

(Branco) e T3: água destilada estéril

Tabela 4. Efeito do extrato fúngico bruto produzido por Cercospora brachiata sobre o desenvolvimento de parte aérea e sistema radicular de Cucumis sativus em diferentes estádios fenológicos

Pepino (Cucumis sativus)

\begin{tabular}{|c|c|c|c|}
\hline Estádio Fenológico & 2 (folhas) & 4 (folhas) & 6 (folhas) \\
\hline Tratamentos & \multicolumn{3}{|c|}{ Altura de parte aérea $(\mathrm{cm})$} \\
\hline $\mathrm{T} 1$ & $57,90 \mathrm{~A}$ & $70,00 \mathrm{~A}$ & $69,80 \mathrm{~A}$ \\
\hline T2 & $53,60 \mathrm{~A}$ & $58,00 \mathrm{~A}$ & $74,80 \mathrm{~A}$ \\
\hline T3 & $48,00 \mathrm{~A}$ & $60,77 \mathrm{~A}$ & $69,40 \mathrm{~A}$ \\
\hline & \multicolumn{3}{|c|}{ Comprimento de Raiz (cm) } \\
\hline T1 & $59,60 \mathrm{~A}$ & $70,06 \mathrm{~A}$ & $62,40 \mathrm{~A}$ \\
\hline T2 & $55,70 \mathrm{~A}$ & $63,40 \mathrm{~A}$ & $62,00 \mathrm{~A}$ \\
\hline T3 & $44,80 \mathrm{~A}$ & $78,80 \mathrm{~A}$ & $60,80 \mathrm{~A}$ \\
\hline & \multicolumn{3}{|c|}{ Peso fresco da parte aérea $(\mathrm{g})$} \\
\hline T1 & $55,23 \mathrm{~A}$ & $66,69 \mathrm{~A}$ & $82,13 \mathrm{~A}$ \\
\hline T2 & $54,04 \mathrm{~A}$ & $64,12 \mathrm{~A}$ & $77,55 \mathrm{~A}$ \\
\hline T3 & 49,06 A & $65,91 \mathrm{~A}$ & $63,77 \mathrm{~A}$ \\
\hline & \multicolumn{3}{|c|}{ Peso fresco da raiz $(\mathrm{g})$} \\
\hline T1 & $15,82 \mathrm{~A}$ & $19,59 \mathrm{~A}$ & $15,33 \mathrm{~A}$ \\
\hline T2 & $18,82 \mathrm{~A}$ & $18,04 \mathrm{~A}$ & $12,64 \mathrm{~A}$ \\
\hline T3 & $9,93 \mathrm{~A}$ & $15,57 \mathrm{~A}$ & $15,26 \mathrm{~A}$ \\
\hline & \multicolumn{3}{|c|}{ Peso seco da parte aérea (g) } \\
\hline T1 & $6,72 \mathrm{~A}$ & $7,52 \mathrm{~A}$ & $9,53 \mathrm{AB}$ \\
\hline T2 & $6,73 \mathrm{~A}$ & $7,09 \mathrm{~A}$ & $13,66 \mathrm{~A}$ \\
\hline T3 & $6,02 \mathrm{~A}$ & $7,15 \mathrm{~A}$ & $8,15 \mathrm{~B}$ \\
\hline & \multicolumn{3}{|c|}{ Peso seco da raiz (g) } \\
\hline T1 & $1,102 \mathrm{~A}$ & $1,25 \mathrm{~A}$ & $1,16 \mathrm{~A}$ \\
\hline T2 & $1,310 \mathrm{~A}$ & $1,108 \mathrm{~A}$ & $1,16 \mathrm{~A}$ \\
\hline T3 & $0,850 \mathrm{~A}$ & $0,86 \mathrm{~A}$ & $0,86 \mathrm{~A}$ \\
\hline & \multicolumn{3}{|c|}{ Clorofila A } \\
\hline T1 & $33,18 \mathrm{~A}$ & $33,38 \mathrm{~A}$ & $31,98 \mathrm{~A}$ \\
\hline T2 & $33,28 \mathrm{~A}$ & $33,62 \mathrm{~A}$ & $33,94 \mathrm{~A}$ \\
\hline T3 & $34,40 \mathrm{~A}$ & $33,52 \mathrm{~A}$ & $32,64 \mathrm{~A}$ \\
\hline & \multicolumn{3}{|c|}{ Clorofila B } \\
\hline T1 & $14,26 \mathrm{~A}$ & $11,28 \mathrm{~A}$ & $12,40 \mathrm{~A}$ \\
\hline T2 & $11,58 \mathrm{~A}$ & $12,86 \mathrm{~A}$ & $12,94 \mathrm{~A}$ \\
\hline T3 & $13,30 \mathrm{~A}$ & $11,96 \mathrm{~A}$ & $12,42 \mathrm{~A}$ \\
\hline
\end{tabular}

Agrarian, Dourados, v. 13, n. 49, p. 339-351, 2020.

Este obra está licenciada com uma Licença Creative Commons Atribuição-NãoComercial-CompartilhaIgual 3.0 Brasil. 
* Médias seguidas pela mesma letra maiúscula na coluna não diferem entre si pelo teste de Tukey a 5\% de probabilidade. T1: extrato bruto extraído com acetato de etila diluído em dimetilsulfóxido $\left(\mathrm{CH}_{3}\right)_{2} \mathrm{SO}-0,1 \mathrm{~g} / \mathrm{L} ; \mathrm{T} 2$ : água destilada com dimetilsulfóxido $\left(\mathrm{CH}_{3}\right)_{2} \mathrm{SO}-0,1 \mathrm{~g} / \mathrm{L}$ (Branco) e T3: água destilada estéril

Tabela 5. Efeito do extrato fúngico bruto produzido por Cercospora brachiata sobre o desenvolvimento de parte aérea e sistema radicular de Sorghum bicolor em diferentes estádios fenológicos

Sorgo (Sorghum bicolor)

\begin{tabular}{|c|c|c|c|}
\hline Estádio Fenológico & 2 (folhas) & 4 (folhas) & 6 (folhas) \\
\hline Tratamentos & \multicolumn{3}{|c|}{ Altura de parte aérea $(\mathrm{cm})$} \\
\hline $\mathrm{T} 1$ & $57,30 \mathrm{~A}$ & $57,2 \mathrm{~A}$ & $84,20 \mathrm{AB}$ \\
\hline T2 & $54,52 \mathrm{~A}$ & $66,2 \mathrm{~A}$ & $91,00 \mathrm{~A}$ \\
\hline \multirow[t]{2}{*}{ T3 } & $49,06 \mathrm{~A}$ & $61,1 \mathrm{~A}$ & $79,40 \mathrm{~B}$ \\
\hline & \multicolumn{3}{|c|}{ Comprimento da raiz $(\mathrm{cm})$} \\
\hline T1 & $58,02 \mathrm{~A}$ & $58,02 \mathrm{~A}$ & $74,40 \mathrm{~A}$ \\
\hline T2 & $65,08 \mathrm{~A}$ & $65,52 \mathrm{~A}$ & $70,00 \mathrm{~A}$ \\
\hline \multirow[t]{2}{*}{ T3 } & $60,98 \mathrm{~A}$ & $64,00 \mathrm{~A}$ & $80,60 \mathrm{~A}$ \\
\hline & \multicolumn{3}{|c|}{ Peso fresco da parte aérea (g) } \\
\hline T1 & $40,47 \mathrm{~A}$ & $42,37 \mathrm{~A}$ & $51,07 \mathrm{~A}$ \\
\hline T2 & $41,80 \mathrm{~A}$ & $48,04 \mathrm{~A}$ & $63,33 \mathrm{~A}$ \\
\hline \multirow[t]{2}{*}{ T3 } & $33,10 \mathrm{~A}$ & $38,34 \mathrm{~A}$ & $56,07 \mathrm{~A}$ \\
\hline & \multicolumn{3}{|c|}{ Peso fresco de raiz (g) } \\
\hline T1 & $30,02 \mathrm{~A}$ & $42,96 \mathrm{~A}$ & $27,12 \mathrm{~A}$ \\
\hline T2 & $40,20 \mathrm{~A}$ & $38,17 \mathrm{~A}$ & $33,99 \mathrm{~A}$ \\
\hline \multirow[t]{2}{*}{ T3 } & $25,52 \mathrm{~B}$ & $32,40 \mathrm{~A}$ & $32,84 \mathrm{~A}$ \\
\hline & \multicolumn{3}{|c|}{ Peso seco da parte aérea (g) } \\
\hline T1 & $5,76 \mathrm{~A}$ & $8,48 \mathrm{~A}$ & $21,40 \mathrm{~A}$ \\
\hline T2 & $4,34 \mathrm{~A}$ & $8,41 \mathrm{~A}$ & $23,35 \mathrm{~A}$ \\
\hline T3 & $5,35 \mathrm{~A}$ & $9,31 \mathrm{~A}$ & $24,44 \mathrm{~A}$ \\
\hline & \multicolumn{3}{|c|}{ Peso seco da raiz (g) } \\
\hline T1 & $2,97 \mathrm{~A}$ & $33,06 \mathrm{~A}$ & $11,32 \mathrm{~A}$ \\
\hline T2 & $2,77 \mathrm{~A}$ & $32,86 \mathrm{~A}$ & $11,62 \mathrm{~A}$ \\
\hline T3 & $3,83 \mathrm{~A}$ & $31,62 \mathrm{~A}$ & $11,50 \mathrm{~A}$ \\
\hline \multicolumn{4}{|c|}{ Clorofila A } \\
\hline T1 & $3,19 \mathrm{~A}$ & $28,50 \mathrm{~A}$ & $10,60 \mathrm{~A}$ \\
\hline T2 & $3,35 \mathrm{~A}$ & $28,04 \mathrm{~A}$ & $9,10 \mathrm{~A}$ \\
\hline T3 & $3,38 \mathrm{~A}$ & $29,40 \mathrm{~A}$ & $9,58 \mathrm{~A}$ \\
\hline \multicolumn{4}{|c|}{ Clorofila B } \\
\hline T1 & $4,73 \mathrm{~A}$ & $30,62 \mathrm{~A}$ & $11,14 \mathrm{~A}$ \\
\hline T2 & $4,03 \mathrm{~A}$ & $30,04 \mathrm{~A}$ & $11,06 \mathrm{~A}$ \\
\hline T3 & $4,01 \mathrm{~A}$ & $31,30 \mathrm{~A}$ & $11,34 \mathrm{~A}$ \\
\hline
\end{tabular}

* Médias seguidas pela mesma letra maiúscula na coluna não diferem entre si pelo teste de Tukey a 5\% de probabilidade. T1: extrato bruto extraído com acetato de etila diluído em dimetilsulfóxido $\left(\mathrm{CH}_{3}\right)_{2} \mathrm{SO}-0,1 \mathrm{~g} / \mathrm{L} ; \mathrm{T} 2$ : água destilada com dimetilsulfóxido $\left(\mathrm{CH}_{3}\right)_{2} \mathrm{SO}-0,1 \mathrm{~g} / \mathrm{L}$ (Branco) e T3: água destilada estéril

Alguns autores também obtiveram resultados quando se utilizou metabólitos fúngicos visando inibições no desenvolvimento de plantas daninhas. Javaid et al. (2017) avaliaram o efeito de metabólitos fúngicos de Alternaria japonica no manejo de Parthenium hysterophorus, em duas concentrações, original (X) e concentrado $(2 \mathrm{X})$. Os metabólitos original e concentrado reduziram o comprimento da parte aérea em $36 \%$ e $70 \%$ em plantas de $P$. hysterophorus com uma semana de idade; e em $22 \%$ e $47 \%$ em plantas com duas semanas de idade, respectivamente. Além disso, reduziu em $40 \%$ e $48 \%$ a biomassa seca da parte aérea em plantas com uma semana de idade e $31 \%$ e $43 \%$ em plantas com duas semanas de idade, respectivamente. 
Javaid e Ali (2011), avaliaram a efetividade de metabólitos de espécies de Trichoderma no controle de Avena fatua L., nas concentrações original $(100 \%)$ e diluído $(50 \%)$. Os filtrados de T. harzianum, $T$. pseudokoningii e $T$. reesei reduziram o crescimento de $A$. fatua, entre $9-56 \%$ na biomassa da parte aérea, em plantas com 1 semana de emergência.

A pulverização de metabólitos fúngicos de C. brachiata (T1) não afetou nenhum parâmetro fisiológico avaliado tanto para pepino quanto para sorgo (Tabelas 4 e 5).

Trata-se provavelmente de metabólitos seletivos às espécies de Amaranthus. Nos estudos de aspectos genéticos e bioquímicos de interações planta-micro-organismos, envolvendo fungos que liberam toxinas seletivas ao hospedeiro, suscetibilidade ou resistência estão sempre relacionadas à sensibilidade ou insensibilidade à toxina, respectivamente (Knogge, 1996). Assim, estas toxinas seletivas representam fatores de patogenicidade, ou seja, são essenciais para o estabelecimento do patógeno no hospedeiro e para a manifestação dos sintomas. Isto foi demonstrado para a toxina HMT, produzida por Cochliobolus heterostrophus (Helminthosporium maydis raça T), para a toxina victorina, produzida por Cochliobolus victoriae, para a toxina PM, produzida por Phyllosticta maydis e para a toxina AAL, produzida por Alternaria alternata, entre outros casos (Buiatti \& Ingram, 1991).

Já as toxinas não seletivas ao hospedeiro agem primariamente inibindo os processos de defesa das plantas, como a detoxificação ou a atividade de enzimas localizadas na membrana (Knogge, 1996). São tóxicas a várias espécies de plantas, independentemente de as mesmas serem ou não hospedeiras do fungo fitopatogênico e são vistas como fatores de virulência, por contribuírem para a severidade da doença sem serem essenciais para sua ocorrência. Dentre tantos exemplos, podem ser citadas a tentoxina, produzida por Alternaria tenuis do algodoeiro, a cercosporina, por Cercospora beticola da beterraba, o ácido oxálico, por Endothia parasitica da castanheira e por Sclerotium spp. de inúmeras espécies vegetais (Pascholati, 1995).

Novos estudos em micro-parcelas em condições de campo devem ser realizados para corroborar o efeito herbicida de metabólitos de $C$. brachiata sobre $A$. viridis em pré e pós-emergência, assim como para outras espécies do gênero Amaranthus e outras espécies de plantas daninhas importantes para a agricultura brasileira.

\section{Conclusões} caruru.

O extrato da cultura de C. brachiata em acetato de etila inibiu em $100 \%$ a germinação de sementes de

Os ácidos graxos de cadeia longa e ésteres de ácidos graxos identificados a partir do filtrado de cultura de C. brachiata em acetato de etila provavelmente são as substâncias responsáveis pela inibição total da germinação das sementes de caruru.

Metabólitos de C. brachiata apresentam atividade inibitória sobre o crescimento de plantas de Amaranthus viridis.

Metabólitos de C. brachiata não afetaram nenhum parâmetro agronômico avaliado para pepino e para sorgo.

\section{Referências}

BASHIR, U.; KHAN, A.; JAVAID, A. Herbicidal Activity of Aspergillus niger Metabolites Against Parthenium Weed. Planta Daninha, v. 36, n. 0, p.1-9, 2018.

BRASIL. Ministério da Agricultura, Pecuária e Abastecimento. Regras para análise de sementes. Secretaria de Defesa Agropecuária. Brasília,DF: MAPA/ACS, 2009. 395 p.

BUIATTI, M.; INGRAM, D. S. Phytotoxins as tools in breeding and selection of disease resistant plants. Experientia, v. 47, p. 811-819, 1991.

CARVALHO, S. J. P.; LÓPEZ-OVEJERO, R. F.; CHRISTOFFOLETI, P. J. Crescimento e desenvolvimento de cinco espécies de plantas daninhas do gênero Amaranthus. Bragantia, v. 67, n. 2, p. 317-326, 2008. 


\section{(2)AGRARI}

CHARUDATTAN, R.; DINOOR, A. Biological control of weeds using plant pathogens: accomplishments and limitations. Crop Protection, v.19, p. 691-695, 1991.

CONTE, D. Ocorrência e controle de Andropogon bicornis e Chloris distichophylla no município de Horizontina-Rs. 2017. Ano de obtenção: 2017. 40 f. Dissertação (Mestrado) - Universidade de Cruz Alta, UNICRUZ, 2017.

FARGUES, J. Effect of liquid culture media on morfology, growth, propagule production, and pathogenic activity of the Hyphomycete, Metarhizium flavoviride. Mycopathologia, v. 15, n. 3, p. 127-138, 2001.

FELISBINO, J.K.R.P. Identificação de substâncias produzidas pelos fungos Cercospora brachiata, Beauveria bassiana e Verticillium sp e avaliação da atividade antibacteriana. $111 \mathrm{f}$. 2019. Dissertação do Programa de Pós-Graduação em Química (Mestrado em Química) - Universidade Federal de Uberlândia, Uberlândia, 2019.

FRANCISCHINI, A.C.; CONSTANTIN, J.; OLIVEIRA JR.; R.S.; SANTOS, G.; BRAZ, G.B.P; DAN, H.A. Primeiro relato de resistência de Amaranthus viridis a herbicidas. Planta daninha, vol.32, n.3, p.571-578, 2014.

GOSSLER, G. K.; FARIAS, H, de S.; SILVA, B. M. da; ZANDONÁ, R. R.; ANDRES, A.; AGOSTINETTO, D. Controle químico tardio de Conyza sp. em áreas de várzea do Rio Grande do Sul. In: CONGRESSO BRASILEIRO DE ARROZ IRRIGADO, 9., 2015, Pelotas. Ciência e tecnologia para otimização da orizicultura: anais. Brasília, DF: Embrapa; Pelotas: Sosbai, 2015.

JAVAID. A.; ALI. S. Alternative management of a problematic weed of wheat Avena fatua L. by metabolites of Trichoderma spp. Chilean J Agric Res, vol. 71, n.2, p. 205-211, 2011.

JAVAID. A.; SHOAIB. A.; AKBAR. M; Herbicidal potential of Drechslera spp. culture filtrates against Parthenium hysterophorus L. Chilean Journal of Agricultural Research, vol. 71, p. 634-637, 2011.

JAVAID A.; MUBEEN. T.; BASHIR. U.; SHOAIB.A. Management of parthenium weed using metabolites of Alternaria japonica. Planta Daninha, vol.35, 2017.

KNOGGE, W. Molecular basis of specificity in host-fungus interactions. European Journal of Plant Pathology, v. 102, p. 807-816, 1996.

LYNCH, F. J.; GEOGHEGAN, M. J. Production of cercosporin by Cercospora species. Transactions of the British Mycological Society, v. 69, n. 3, p. 496-498, 1977.

MACIAS, F. A.; CASTELLANO. D.; MOLINILLO. J.M. Search for a standard phytotoxic bioassay for allelochemicals. Selection of standard target species. Journal of Agricultural and Food Chemistry, v. 48, n. 6, p. 2512-2521, 2000.

OLIVEIRA, M. F. de; BRIGHENTI, A. M. Controle de Plantas Daninhas: Métodos físico, mecânico, cultural, biológico e alelopatia. 1 ed. Brasília, DF: Embrapa Milho e Sorgo, 2018. 196 p.

PASCHOLATI, S. F. Fitopatógenos: fitotoxinas e hormônios. In: BERGAMIM FILHO, A.; KIMATI, H.; AMORIM, L. 3 Ed. Manual de fitopatologia: princípios e conceitos. Piracicaba: Ceres, 1995. v.1, p.365-392.

PASSOS, J.L.; BARBOSA, L.C.A.; DEMUNER, A.J.; BARRETO, R.W. KING-DIAZ, B.; LOTINA-HENNSEN, B. Effects of Corynespora cassiicola on Lantana câmara. Planta Daninha, vol.28, n.2, pp.229-237, 2010.

SANTOS, L. S.; OLIVEIRA. M. N.; GUILHON, G. M. S. P.; SANTOS, A. S.; FERREIRA, I. C. S.; LOPESJÚNIOR, M. L.; ARRUDA, M. S. P.; SAILVA, M. N.; SOUZA FILHO, A. P. S.; RODRIGUES-FILHO, E.; OLIVEIRA, M. C. F. Potencial herbicida da biomassa e de substâncias químicas produzidas pelo fungo endofítico Pestalotiopsis guepinii. Planta Daninha, v. 26, n. 3, p. 539-548, 2008.

SOUZA FILHO, A. P. S., e M. L. R. DUARTE. Atividade alelopática do filtrado de cultura produzido por Fusarium solani. Planta Daninha, Viçosa, v. 25, n 1, p. 227-30, 2007. 
